\section{AL-AZHAR}

Assiut Dental Journal
The Official Publication of The

Faculty of Dental medicine.

Al-Azhar Assiut Uniuersity.

Egypt

\title{
Influence of Different Preparation Designs on Fracture Resistance of Full-Coverage Occlusal Veneers After Thermo-Mechanical Aging Simulation
}

\section{Suad M Hassan *1, Walaa El Mekkawi ${ }^{1}$}

Codex : 18/2020/10

Aadj@azhar.edu.eg

\section{KEYWORDS}

CAD/CAM, Lithium disilicate, Occlusal veneers, Fracture resistance, Preparation designs.

\begin{abstract}
Aim: To evaluate the fracture resistance maxillary molars restored with lithium disilicate glass-ceramic (LDG) occlusal veneers with two preparation designs. Subjects and methods: Twenty extracted maxillary molars were assigned to two groups ( $\mathrm{n}=$ 10). In group 1 (GROUP S ), the teeth received a preparation for a conservative fullcoverage occlusal veneer restoration with a 90 rounded shoulder margin. In group 2 (GROUP c), were prepared with a minimally invasive chamfer. LDG restorations (IPS e.max CAD) were obtained with the Cerec 3 CAD/CAM system and luted with Variolink II cement. After thermo-mechanical aging (120,000 cycle with vertical movement $1 \mathrm{~mm}$, horizontal movement $3 \mathrm{~mm}$ and frequency $1.6 \mathrm{~Hz}$ ), All the samples were individually mounted on the Instron testing machine with a load cell of $5 \mathrm{KN}$ and fracture test was done by compressive mode of load applied occlusally using a metallic rod with spherical tip (5.6 mm diameter) at cross-head speed of $1 \mathrm{~mm} / \mathrm{min}$. The load required to fracture was recorded in Newton and tabulated to be statistically analyzed. The fractured specimens were examined to detect the mode of failure. Results: The fracture resistance of samples with chamfer finish line (2453.2 $\mathrm{N} \pm 104.83)$ was higher than the values of samples with shoulder finish line (2440.6 N \pm 119.36$)$ but with no statistical significant difference ( $p$ value $>0.05$ ). Most of the observed specimens exhibited restorable fractures. Conclusion: This study demonstrated similar satisfactory performance of the two considered preparations designs for occlusal veneer with lithium disilicate glass-ceramic. Conclusion: A new minimally invasive occlusal veneer preparation with marginal chamfer exhibited encouraging fracture resistance that were comparable to those of a standard conservative preparation for the restoration of molars with CAD/CAM lithium disilicate occlusal veneers.
\end{abstract}

\section{INTRODUCTION}

The gradual wear of occlusal surfaces of teeth is a normal progressive process during life. However, pathologic excessive tooth wear of occlusal surface can result in pulpal pathology, occlusal disharmony, impaired function, and esthetic disfigurement. The etiology of tooth 
wear is multifactorial and associated with dietary habits, medical conditions, and oral habits that lead to attrition and abrasion of the enamel and dentine.

(1) The recommended treatments to restore molars and premolars with severe erosion are indirect composite resin or ceramic restorations, such as inlays, onlays, or full crowns. However, some of these approaches can be very invasive. ${ }^{(2)}$

Obtaining excellent esthetic results without abandoning to the preservation of the biological structures is one of the main goals of modern restorative dentistry. In both the clinical and laboratory setting, the restorative protocols have become simpler, predictable, and capable of providing satisfactory esthetic and functional results. The use of new generation all-ceramic restorations and adhesive systems can lead to improved preservation of the residual tooth structures, especially for the treatment of the single tooth. ${ }^{(3,4)}$

Occlusal veneers are a contemporary restorative approach indicated for teeth with occlusal wear The main advantage of occlusal veneers is the recovery of the masticatory function with maximum preservation of dental structure being a conservative option compared to traditional onlays and complete coverage crowns.

A recent study used 3D color holography to evaluate the behavior of a molar occlusal veneer under stress in addition to the response of the prepared tooth. Occlusal surface of a lower molar was prepared to receive a specific monolithic ceramic reconstruction manufactured with a chair side CAD/ CAM system. Longitudinally cut samples were used to get a planar object observation and to "look inside" the tooth. A Digital holographic set-up permits to obtain the contact-less and one-shot measurement of the three-dimensional displacement field at the surface of the tooth sample; stain fields were evaluated with low noise-sensitive computation. The results showed an excellent behavior of the restored tooth without areas of excessive stress concentrations, and it was therefore concluded that ceramic occlusal veneers behave in accordance with the biomechanical concepts ensuring the longevity of the reconstituted tooth. ${ }^{(5)}$

Lithium disilicate glass-ceramic (LDG) is a recently announced ceramic material composed of quartz, lithium dioxide, phosphor oxide, alumina, potassium oxide and other components, characterized by flexural strength up to $440 \mathrm{MPa} .{ }^{(6)}$ The mechanical stability of LDG ceramic is assured by the embedment of lithium disilicate crystals ( $\mathrm{SiO} 2-$ Li2O) into a matrix of glass that minimizes microcrack propagation. ${ }^{(7)}$ The first available and most tested commercial product belonging to the class of LDG materials is IPS e.max lithium disilicate, introduced in 2005 by Ivoclar Vivadent.

Different factors play a significant role in determining the fracture resistance of all-ceramic restorations. The luting technique has an influence in this regard as adhesively bonded all-ceramic restorations are characterized by greater fracture resistance than traditionally cemented restorations. ${ }^{\left({ }^{8,9}\right)}$ Depending on the adhesive system being used, adhesive restorations bonded making use of total-etch techniques can reach a bond strength up to $28 \mathrm{MPa}$ within enamel ${ }^{(10)}$ and 13 to $20 \mathrm{MPa}$ within dentin. ${ }^{(11)}$ Immediate sealing of the freshly cut dentin has been suggested to improve bond strength.

The increased thickness of the ceramic restoration is confidently another factor affecting positively its fracture resistance, ${ }^{(12)}$ but the modern minimally invasive concepts of restorative and prosthetic dentistry often inflict the use of thin occlusal restorations. Bonded occlusal veneers made of e.max CAD were found to resist to forces of up to $800 \mathrm{~N}$ and $1000 \mathrm{~N}$, when their thickness was $0.6-1.0 \mathrm{~mm}$ or $1.2-1.8 \mathrm{~mm}$, respectively ${ }^{(13)}$; these values are only slightly inferior to those of monolithic full crowns of comparable thickness. ${ }^{(14)}$ The use of ultrathin LDG occlusal veneers $(0.6 \mathrm{~mm})$ has been reported to be a promising and viable restorative procedure. ${ }^{(15)}$ Further, Guess et al. ${ }^{(16)}$ reported no significant effect on the fracture resistance of pressable LDG ce- 
ramic onlay restorations on premolars reducing the preparation depth to 1.00 and $0.5 \mathrm{~mm}$.

The preparation design is another factor potentially capable of influencing the fracture resistance of all-ceramic restorations. Minimally invasive designs or the "no-preparation" approach have been advocated for teeth where a significant amount of dental tissue has already been lost by wear and erosion, because additional tooth preparation may results in more destruction in the remaining tooth structure these. ${ }^{(15)}$ Although there is some evidence dissuading from the use of LDG single crowns with feather edge preparation in frontal teeth due to marginal crack formation, ${ }^{(17)}$ but little is known about the rendering of LDG occlusal veneers with reduced marginal thickness.

An in vitro study on occlusal veneer was to evaluate and compare the effect of using different finishing line designs (deep chamfer and shoulder) with different occlusal surface reduction schemes (planar and flat) on the vertical marginal fit of full contour CAD/CAM zirconia crown restoration . Teeth were divided into two main groups according to the design of finishing line used. They found that statistically highly significant differences $(\mathrm{p}<0.01)$ using one- way ANOVA analysis. They concluded Deep chamfer with planar occlusal reduction scheme provided better marginal fit compared to that obtained with shoulder. ${ }^{(18)}$

The purpose of this study was to evaluate the influence of two different occlusal veneer prepara- tions on the fracture resistance of maxillary molars restored using monolithic lithium disilicate after chewing simulation. A rounded 90 shoulder was compared to a new minimally invasive chamfer design. The following hypothesis were tested: there is no difference in the load to fracture, fracture pattern between the two preparation designs.

\section{MATERIALS AND METHODS}

\section{Teeth Selection:}

Twenty $(\mathrm{N}=20)$ freshly extracted permanent, caries and defect free human maxillary first molars were selected in accordance with guidelines from research ethics committee approval of Faculty of Dental Medicine,Al-Azhar University. Selected molars had similar dimensions measured using a digital caliper; crown mesiodistal width $(10.5 \pm 1.0 \mathrm{~mm})$ crown buccolingual width $(11.5 \pm 1.0 \mathrm{~mm})$ measured at the level of maximum convexity of the cemento-enamel junction. Selected molars had overall length, $20.0 \pm 1.0 \mathrm{~mm}$.

The teeth were cleaned from any calculus deposits and debris by using an ultrasonic scaler and were examined for any cracks. Then, the teeth were immersed into a 5\% sodium hypochlorite solution for 15 minutes and stored in saline. The teeth were randomly assigned to two test groups of ten elements each according to the preparation technique to receive a full-coverage lithium disilicate occlusal veneer. (FIGURE 1)

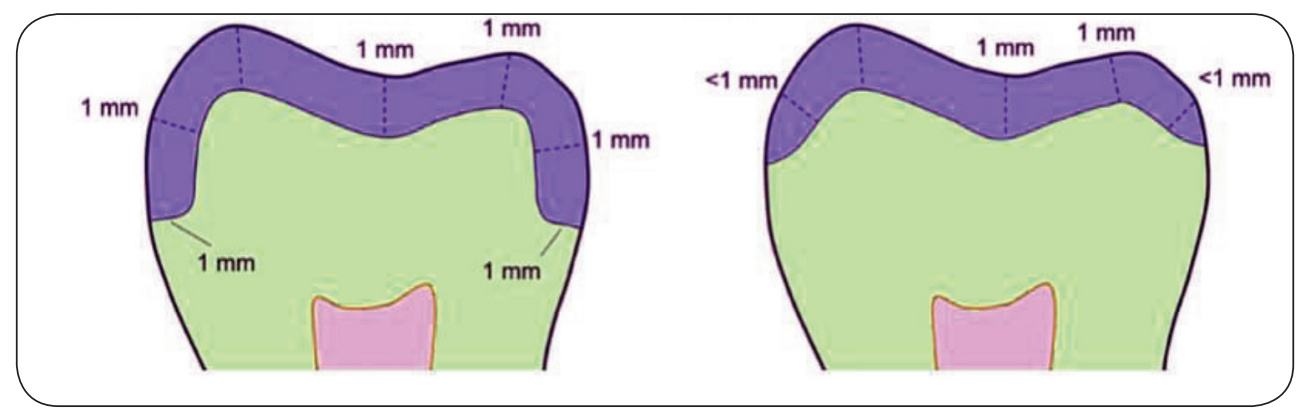

Fig. (1) 90_ rounded shoulder (A) \& minimally invasive chamfer (B) 
- Group (S): Ten molars $(\mathrm{n}=10)$ were prepared with a rounded 90 shoulder finish.

- Group (c): Ten molars $(\mathrm{n}=10)$ were prepared with a minimally invasive chamfer.

\section{Construction of epoxy-resin blocks:}

Plastic (PVC) cylinders $20 \mathrm{~mm}$ in diameter and $20 \mathrm{~mm}$ in length were used as molds for constructing epoxy resin blocks. The mold was centralized and fixed to the lower table of a dental surveyor at zero tilt (horizontal position). Each tooth was attached with sticky wax to the surveyor rod. The tooth, vertical element of the surveyor and the outer surface of the plastic cylinder were aligned to be parallel to each other with the tooth lying in the center of the plastic cylinder. The recommended proportions of polymer and monomer of epoxy resin were mixed (2:1) according to the manufacturer's recommendations in a plastic container, then the mix was poured in the mold. The tooth was then lowered into the center of the cylinder, to be embedded in the epoxy resin up to $2 \mathrm{~mm}$ below the cervical line exposed to simulate the biologic width. The epoxy resin was left to set till complete polymerization for 24 hours. The blocks were then removed from the plastic cylinders, then they were finished and smoothened.

\section{Tooth preparation}

The occlusal reduction for both groups was set at $1 \mathrm{~mm}$, following the indications about the minimum occlusal thickness for the final restoration given by the manufacturer of the lithium disilicate $\mathrm{CAD} /$ CAM blocks used in the present study (IPS e. max, Ivoclar Vivadent, Schaan, Liechtenstein). For each tooth, two silicon indexes were obtained to check the occlusal reduction in mesiodistal and buccolingual direction.

- Group (S): rounded 90_ shoulder (Figure 1A). Depth grooves were placed all over the occlusal surface of the tooth following the original anatomy with a cylindrical coarse diamond bur (835 KRM 123008, Komet, Germany) with a $0.8 \mathrm{~mm}$ diameter. The guiding grooves were connected by removing the enamel septa between the grooves with a conical bur (846 KR 314 016, Komet). The occlusal preparation was finished with a fine-grit diamond bur. A wider roundended cylindrical diamond bur was used to prepare the axial walls creating a 90_ shoulder finish line, which was finished with a fine-grit bur. The prepared surfaces were then polished with abrasive rubber points (9608 314 030, Komet).

- Group (S): minimally invasive chamfer technique (Figure 1B). The occlusal reduction was carried out as described in G1. The marginal chamfer was prepared on the top of the axial wall with the aid of a specific tapered bur with a noncutting guide pin at its tip (6856P 314 018,Komet) and finished with a fine-grit bur (8856 P 314 018, Komet; Figure 2). The prepared surfaces were polished as described above.

\section{Fabrication of the occlusal veneers:}

All occlusal veneers were fabricated using CEREC AC CAD/CAM system, A bio-generic individual design was selected to allow designing the restoration from the software database so that all occlusal veneers would have the same anatomy dimensions. Prepared teeth were scanned using Omnicam camera. Twenty occlusal veneers were milled from an equal number of lithium disilicate blocks (IPS e.max $\mathrm{CAD}$ ) following the same principles already described by Magne et al. ${ }^{(19)}$ After milling, each restoration was carefully examined for any cracks were observed. After manufacturing, the internal surface of each restoration was acid-etched with buffered 9\% hydrofluoric acid for 20 seconds, then rinsed with water spray for 20 seconds. Post-etching cleaning was performed with $37 \%$ orthophosphoric acid (Fill Etch, Dental World, Italy). After 60 seconds, the gel was rinsed with water spray for the same amount of time and the restoration left to dried, then a silane primer (Monobond Plus, Ivoclar Vivadent) was applied onto the inner surface of each veneer and gently dried with air. 


\section{Cementation of the occlusal veneers:}

The prepared tooth surfaces were treated with an intraoral sandblaster (Cojet System, 3M,St. Paul, Minnesota). The enamel margins were covered with an etchant gel containing 37\% orthophosphoric acid (Fill Etch, DentalWorld), which

was rinsed after 30 seconds. Both the internal surface of the restoration and the prepared tooth were covered with adhesive resin. The two components of a dual-cure resin luting cement (Variolink II, shade A3.5, Ivoclar-Vivadent) were mixed in a 1:1 ratio and placed onto the treated veneer surface. All samples were placed under $3 \mathrm{~kg}$ weight and then light cured. The excess luting cement extruding at the adhesive interface was removed with a manual instrument. After cementation samples of each group was kept in an incubator at $37^{\circ} \mathrm{C}$ for 24 hours before testing.

\section{Thermomechanical aging:}

The restored samples underwent thermo-mechanical aging using ROBOTA chewing simulator integrated with thermocyclic protocol operated on servo-motor (model ach-09075dc-t, AdTech technology co., Germany). The chewing simulation test included the application of $5 \mathrm{~kg}(49 \mathrm{~N})$ load for 120,000 cycle with vertical movement $1 \mathrm{~mm}$, horizontal movement $3 \mathrm{~mm}$ and frequency $1.6 \mathrm{~Hz} .^{(16)} \mathrm{At}$ the same time, the device subjected the specimens to thermocycles of 80 seconds each in distilled water at $5 \pm 3$ _C e $55 \pm 3$ _C. correct thermo-mechanical loading was checked every 10,000 cycles by monitoring the mechanical action and water temperature within the chewing chambers.

\section{Fracture resistance testing and failure analysis:}

The resistance to fracture of the specimens was tested with a universal testing machine (Quasar,
Galdabini, Cardano al Campo, Italy), (FIGURE 2) which was set to exert an increasing force with a round $5.6 \mathrm{~mm}$ diameter wide stainless steel stylus onto the restored tooth at a speed of $1 \mathrm{~mm} / \mathrm{min}$. ${ }^{(20)}$ The tip of the stylus was positioned over the central fossa to achieve tripodization of contacts along the cuspal inclines The maximum load to fracture was registered and collected in a spreadsheet. The type of fracture was qualitatively assessed and failure mode classification done to distinguishing between failures above or below the cementoenamel junction and between fractures and cracks (fracture without fragment detachment). ${ }^{(21)}$

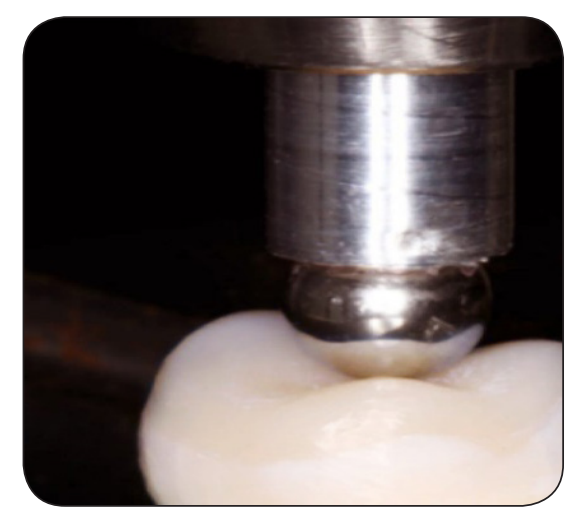

Fig. (2) Load to fracture in the universal testing machine

\section{Statistical analysis:}

Statistical analysis was performed with IBM ${ }^{\circledR}$ SPSS ${ }^{\circledR}$ Statistics Version 25 for Windows. The mean and standard deviation values were calculated for each group. Normality test was performed using Kolmogorov-Smirnov test and revealed normal distribution between values of each group. Homogeneity test was performed using Levene's test and revealed homogenous distribution between all variables. Therefore, 2 -independent sample $\mathrm{T}$ test was performed between the variables (with significance level was set at $\mathrm{P} \leq 0.05$ ) to reveal the statistical significant difference. 


\section{RESULTS}

Table (1): The mean, standard deviation (SD) values $(N)$ and results of $T$ test for comparison between fracture resistances of the two designs.

\begin{tabular}{|c|c|c|}
\hline & Mean $(\mathrm{N})$ & $( \pm \mathrm{SD})$ \\
\hline Shoulder finish line & 2440.60 & $( \pm 119.36)$ \\
\hline Chamfer finish line & 2453.20 & $( \pm 104.83)$ \\
\hline P-Value & 0.864 & \\
\hline
\end{tabular}

The mean difference is statistically significant at the 0.05 level.

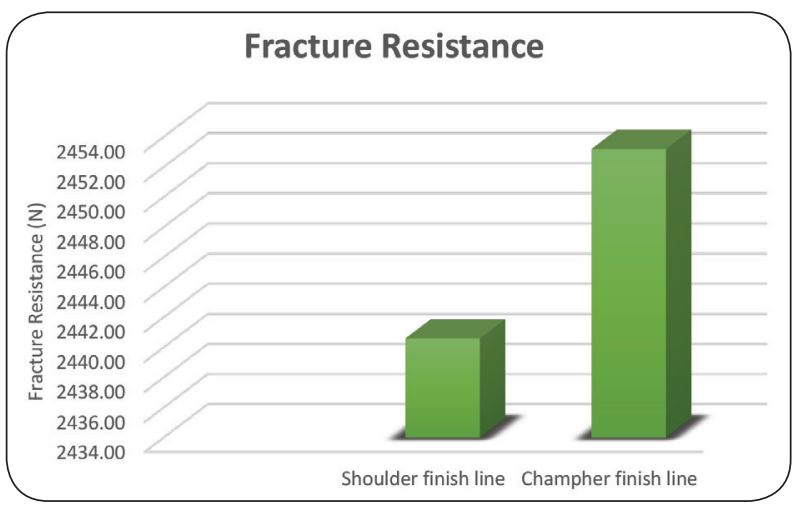

The values of fracture resistance were represented as means and standard deviation. The fracture resistance of samples with chamfer finish line $(2453.2 \mathrm{~N}$ \pm 104.83 ) was higher than the values of samples with shoulder finish line (2440.6 $\mathrm{N} \pm 119.36)$ but with no statistical significant difference ( $\mathrm{p}$ value $>0.05$ ).

\section{Failure Mode Analysis:}

After the samples were subjected to fracture resistance test, they were examined using a magnifying lens under strong lighting condition to detect and characterize the different failure modes. Thorough examination of the twenty samples revealed that the failure findings ranged between small occlusal cracks representing the major number of samples (65\%), followed by the large occlusal cracks involving only the ceramic material $(30 \%)$, and the least was a catastrophic failure that was represented by one sample only $(5 \%)$, which involved the veneer and the epoxy die. Therefore, we classify these failure patterns into three types (Table 2), type I, II, and III,

TABLE (2): Distribution of the failed samples into three types as detected with the two tested designs.

\begin{tabular}{|c|c|c|c|c|}
\hline & Shoulder (10) & $\begin{array}{c}\text { Minimally invasive } \\
\text { Chamfer (10) }\end{array}$ & Total & $\%$ \\
\hline Failure type I & 6 & 7 & 13 & 65 \\
\hline Failure type II & 3 & 3 & 6 & 30 \\
\hline Failure type III & 1 & 0 & 1 & 5 \\
\hline Total & 10 & 10 & 20 & 100 \\
\hline
\end{tabular}

\section{DISCUSSION}

Occlusal veneers have been demonstrated as a conservative alternative to traditional onlays and complete coverage crowns for the treatment of severe abrasive/erosive lesions, with survival rates of
$88.7 \%$ after 17 years ${ }^{(22)}$ and $84 \%$ after 12 years; ${ }^{(23)}$ adhesively bonded ceramic inlays and onlays have demonstrated long-term reliability. As a result, their range of indications has been increased, including treatment of advanced erosion, (24-26) and stabiliza- 
tion of teeth with cracked tooth syndrome. Occlusal veneers are essentially thin overlay restorations with a non-retentive design that allow the conservation of coronal structure, often avoiding the root canal treatment. For this reason, the present investigation was conducted on teeth that intentionally were not endodontically treated.

CAD/CAM technology was selected to construct occlusal veneers in the present study due to its ability to control thickness and anatomy of restorations during the fabrication process. It also allows the standardization of the internal fit of the restoration as well as the mechanical properties of the restorative materials. Many potentially confounding operator variables were avoided such as dental laboratory technicians' skills and procedures involved in the fabrication process. This is especially important when using occlusal veneers. ${ }^{(27)}$ Veneers' standardization was done in the present study by using the biogeneric-copy modeand occlusal anatomy from the software database in the Cerec software 4.4. This procedure ensured standardization of the occlusal veneers among groups of the study.

The success of occlusal veneers depends to a great extent on the constructing material. Selected materials should be able to withstand the high occlusal forces expected, which are associated with other etiological factors leading to loss of occlusal surfaces. These forces are applied in a cyclic manner, increasing their deleterious effect. Selected materials should therefore have the ability to withstand cyclic loads by being fracture resistant. The preparation design is another factor potentially capable of influencing the fracture resistance of allceramic restorations. Minimally invasive designs or the "no-preparation" approach have been advocated for teeth where a significant amount of dental tissue has already been lost by wear and erosion, because additional tooth preparation may results in more destruction in the remaining tooth structure these. ${ }^{(15)}$

Therefore, the aim of the present study was directed to examine the Fracture resistance of CAD/
CAM ceramic materials occlusal veneer with two different preparation designs.

To conduct the present study; natural teeth were used to represent improved clinical situation. human maxillary first molars were selected because they have high frequency of erosion-like wear lesions. ${ }^{(28)}$

Fracture resistance was considered to be the most important and determining factor for the clinical longevity of all-ceramic restorations. Yucel et $\mathrm{al}$, ${ }^{(29)}$ reported that the fracture resistance of all-ceramic restorations depends on modulus of elasticity of the chosen abutment material. Wood et al, ${ }^{(30)}$ and Zahran et al, ${ }^{(31)}$ suggested epoxy resin to be used as a die material for this purpose as it reacts elastically as natural dentin does, therefore, it was chosen in the present investigation.

The null hypotheses that the tested types of preparation technique do not affect load to fracture, fracture pattern, as well as that thermomechanical loading has no influence on the fracture resistance were both accepted.

Waltimo and Kononen, ${ }^{(32)}$ using a novel bite force recorder found that the biting forces in the molar region ranged between $597 \mathrm{~N}$ to $847 \mathrm{~N}$ for young women and men respectively. Gibbs et al, ${ }^{(33)}$ Lundgren and Laurell, ${ }^{(34)}$ reported that normal masticatory forces ranged between $37 \%$ to $40 \%$ of the biting force. In the present research, the mean fracture loads for the two occlusal veneer designswere beyond the range of realistic occlusal forces in the posterior region $(\sim 2446 \mathrm{~N})$ Therefore, it can be assumed that all the tested specimens can withstand the maximum intraoral posterior masticatory forces.

Comparing the results of this study to other investigations on the fracture resistance of lithium disilicate restorations, resistance to load was significantly higher than that reported in a study on premolars restored with lithium disilicate overlays (maximum mean value $1361 \pm 333 \mathrm{~N}$ ). ${ }^{(16)}$ Such difference is possibly attributed to the different tooth type. 
In this study two finishing lines were chosen, a 90_ shoulder and a minimally invasive chamfer, but the marginal preparation design showed no significant influence on the fracture resistance $(\mathrm{P}=0.864)$, which are in accordance with Clausen et al. evaluated the influence of different preparation designs (chamfer finishing line or straight-beveled finishing line) on fracture resistance of adhesively luted nonretentive full-coverage molar restorations, made of lithium or leucite-reinforced glass ceramic, and found no statistically significant differences on the fracture resistance.$^{(35)}$ These findings suggest that the finishing line looks like not to play a primary role in the fracture resistance of partial indirect restoration, provided that no changes in the other variables.

The modes of failure of the two designs ranged mostly between Types I and II (Table 2) which constitutes $65 \%$ and $30 \%$ respectively. These failure modes which reclined between cracks or fractures of the veneer material only without involving the epoxy dies are in agreement with the findings of Magne et al, ${ }^{(19)}$ Johnson et al, ${ }^{(36)}$ and Schlichting et $\mathrm{al},{ }^{(37)}$ who considered failures that are limited to the restorative material improve the longevity prognosis of the restored teeth, since, the occlusal veneer can be easily replaced by milling an identical one. However, one sample only of the shoulder design was recorded as Type III in which catastrophic failure was detected through splitting of the veneer and the epoxy die.

\section{CONCLUSIONS}

In conclusion, the results of the present study support the use of different finish lines preparations for occlusal veneer lithium disilicate with. Further in vivo studies are needed to validate the clinical performance of the more conservative preparation design.

\section{REFERENCES}

1. Lussi A, Hellwig E, Ganss C, Jaeggi T. Buonocore memorial lecture. Dental Erosion: Oper Dent. 2009; $34: 251-62$

2. West NX, Joiner A.: Enamel mineral loss . Journal of Dentistry .2014; 2:11-42.

3. Edelhoff D, Sorensen JA. Tooth structure removal associated with various preparation designs for posterior teeth. Int $\mathrm{J}$ Periodontics Restorative Dent. 2002;22:241-249.

4. Valenti M, Valenti A. Retrospective survival analysis of 261 lithium disilicate crowns in a private general practice. Quintessence Int. 2009;40: 573-579.

5. Xia H, Picart P, Montresor S, Guo R, Li J, Yusuf S, Durand J, Fages M. Mechanical behavior of CAD/CAM occlusal ceramic reconstruction assessed by digital color holography. Dent Mater. 2018; 34: 1222-34

6. Demir N, Ozturk AN, Malkoc MA. Evaluation of the marginal fit of full ceramic crowns by the microcomputed tomography (micro-CT) technique. Eur J Dent. 2014; 8:437-444.

7. Silva NR, Thompson VP, Valverde GB, et al. Comparative reliability analyses of zirconium oxide and lithium disilicate restorations in vitro and in vivo. J Am Dent Assoc. 2011;142(suppl 2):4S-9S.

8. Piwowarczyk A, Bender R, Ottl P, Lauer HC. Long-term bond between dual-polymerizing cementing agents and human hard dental tissue. Dent Mater. 2007;23:211-217.

9. Klosa K, Wolfart S, Lehmann F, Wenz HJ, Kern M. The effect of storage conditions, contamination modes and cleaning procedures on the resin bond strength to lithium disilicate ceramic. J Adhes Dent. 2009;11:127-135.

10. Fortin D, Swift EJ Jr, Denehy GE, Reinhardt JW. Bond strength and microleakage of current dentin adhesives. Dent Mater. 1994;10:253-258.

11. Sarr M, Mine A, De Munck J, et al. Immediate bonding effectiveness of contemporary composite cements to dentin. Clin Oral Investig. 2010;14:569-577.

12. Sorrentino R, Nagasawa $Y$, Infelise $M$, et al. In vitro analysis of the fracture resistance of CAD-CAM monolithic lithium disilicate molar crowns with different occlusal thickness. J Osseointegr. 2018;10: 11-17.

13. Al-Akhali M, Chaar MS, Elsayed A, et al. Fracture resistance of ceramic and polymer-based occlusal veneer restorations. J Mech Behav Biomed Mater. 2017;74:245-250.

14. Andrade JP, Stona D, Bittencourt HR, Borges GA, Burnett LH Júnior, Spohr AM. Effect of different computer-aided 
design/computer-aided manufacturing (CAD/CAM) materials and thicknesses on the fracture resistance of occlusal veneers. Oper Dent. 2018;43:539-548.

15. Schlichting LH, Maia HP, Baratieri LN, Magne P. Noveldesign ultrathin $\mathrm{CAD} / \mathrm{CAM}$ composite resin and ceramic occlusal veneers for the treatment of severe dental erosion. J Prosthet Dent. 2011;105:217-226.

16. Guess PC, Schultheis S, Wolkewitz M, Zhang Y, Strub JR. Influence of preparation design and ceramic thicknesses on fracture resistance and failure modes of premolar partial coverage restorations. J Prosthet Dent. 2013;110:264-273.

17. Fuzzi M, Tricarico MG, Ferrari Cagidiaco E, et al. Nanoleakage and internal adaptation of zirconia and lithium disilicate single crowns with feather edge preparation. J Osseointegr. 2017;9:250-262.

18. Abdullah L, Ibraheem A :The Effect of Finishing Line Designs and Occlusal Surface Reduction Schemes on Vertical Marginal Fit of Full Contour CAD/CAM Zirconia Crown Restorations. International Journal of Dentistry 2017;4: 2378-7090.

19. Magne P, Schlichting LH, Maia HP, Baratieri LN. In vitro fatigue resistance of $\mathrm{CAD} / \mathrm{CAM}$ composite resin and ceramic posterior occlusal veneers. J Prosthet Dent. 2010;104:149-157.

20. Kern M, Strub JR, Lu XY. Wear of composite resin veneering materials in a dual-axis chewing simulator. $\mathrm{J}$ Oral Rehabil. 1999;26:372-378.

21. Goracci C, Cury AH, Cantoro A, Papacchini F, Tay FR, Ferrari M. Microtensile bond strength and interfacial properties of self-etching and self-adhesive resin cements used to lute composite onlays under different seating forces. J Adhes Dent. 2006;8:327-335.

22. Otto $\mathrm{T}$ and Schneider D. Long-term clinical results of chairside Cerec CAD/CAM inlays and onlays: a case series. Int J Prosthodont 2008; 21:53-9

23. Frankenberger R, Taschner M, Garcia-Godoy F, Petschelt A, Krämer N. Leucite-rein-forced glass ceramic inlays and onlays after12 years. J Adhes Dent 2008; 10:393-8.

24. Vailati F. and Belser U. Full-mouth adhesive rehabilitation of a severely eroded dentition: the three-step technique. Part 1. Eur J Esthet Dent 2008; 3:30-44.

25. Vailati F. and Belser U. Full-mouth adhesive rehabilitation of a severely eroded dentition: the three-step technique. Part 2. Eur J Esthet Dent 2008; 3:128-46.
26. Vailati F. and Belser U. Full-mouth adhesive rehabilitation of a severely eroded dentition: the three-step technique. Part 3. Eur J Esthet Dent 2008; 3:236-57.

27. Beuer F, Schweiger J, Edelhoff D. Digital dentistry: an overview of recent developments for CAD/CAM generated restorations. Br Dent J. 2008; 204:505-11.

28. Miyazaki T, Hotta Y .CAD/CAM systems available for the fabrication of crown and bridge restorations. Aust. Dent J; 2011:56, 97-106.

29. Yucel MT, Yondem I, Aykent F, Eraslan O: Influence of the supporting die structures on the fracture strength of allceramic all-ceramic materials. Clin Oral Investigations 2012; 16:1105- 10 .

30. Wood KC, Berzins DW, Luo Q, Thompson GA, Toth JM, and Nagy WW: Resistance to fracture of two all-ceramic crown materials following endodontic access. J Prosthet Dent 2006; 95: 33-41.

31. Zahran M, El-Mowafy O, Tam L, Watson PA and Finery. Fracture strength and fatigue resistance of all-ceramic molar crowns manufactured with CAD/CAM technology. J Prosthodont 2008; 17:370-77.

32. Waltimo A and Kononen M: A novel bite force recorder and maximal isometric bite force values for healthy young adults. Scand J Dent Res 1993; 101: 171-5.

33. Gibbs CH, Mohan PE, Lundeen HC, Brehnan K, Wals EK, and Holbrook WB: Occlusal forces during chewing and swallowing as measured by sound transmission. J Prosthet Dent 1981 ; 46:443-9.

34. Lundgren D, and Laurell L: Occlusal force pattern during chewing and biting in dentition restored with fixed bridges of cross-arch extension. I. Bilateral end abutments. J Oral Rehabil 1986; 13: 57-71.

35. Clausen JO, Abou Tara M, Kern M. Dynamic fatigue and fracture resistance of non-retentive all-ceramic fullcoverage molar restorations.Influence of ceramic material and preparation design. Dent Mater. 2010;26:533-538.

36. Johnson AC, Versluis A, Tantbirojn D, Ahuja S. Fracture strength of CAD/CAM composite and composite-ceramic occlusal veneers. J Prosthodont Res 2014; 58: 107-114.

37. Schlichting LH, Maia HP, Baratieri LN, Magne P. Novel design ultra-thin CAD/CAM composite resin and ceramic occlusal veneers for the treatment of severe dental erosion. J Prosthet Dent 2011; 105: 217-26. 
مجلة أسيوط لطب الأسنان

النشر الرسمي لكلية طب الأسنان جامعة الأزهر أسيوط الكاية

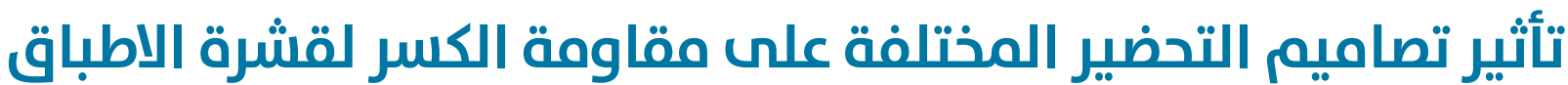 الملتصقة ذات التغطية الكاملة بعد محاكاة الشيخوخة الميكانيكية}

\section{*عحاد محمد حسن, ولاء اسـامه المكاوي}

1. قسـم التيجان والجسـور، كلية طب الاسنان، (بنات - القاهـرة)، جاهعـة الأزهر، هصر

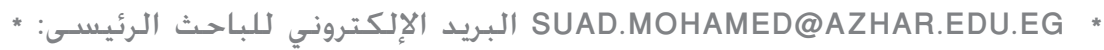

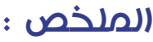

الهـدف: تقييم مقاومة الكسـر لأضراس الفك العلوي التي تم ترميمها باستخـدام قشـور الإطباق الزجاجية الملتصقة المصنعة من الليثيوم داي سيليكات (LDG) مع تصميمين مختلفين للتحضير.

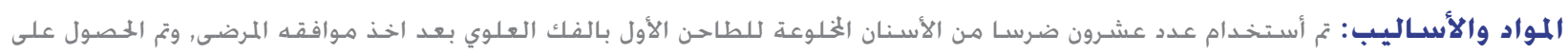

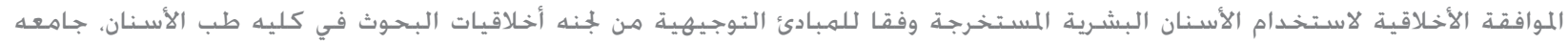

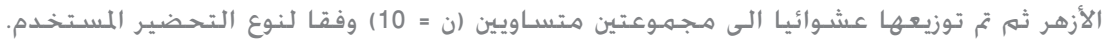

الجُموعة الأولى : تلقت الأسـنان ختضيرًا لاستعادة القشـرة الإطباقية ذات التغطية الكاملة مع خط النهاية الكتفي المستدير 90 درجة.

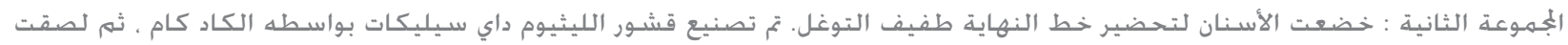

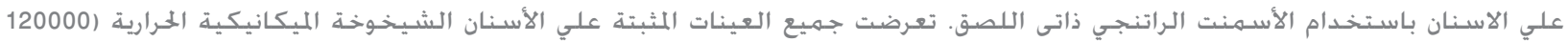

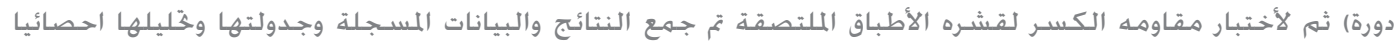

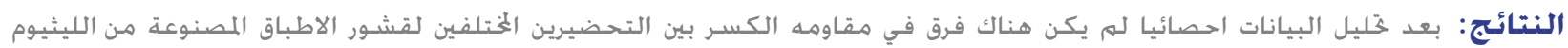

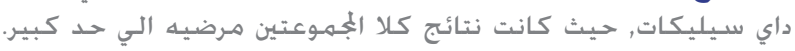

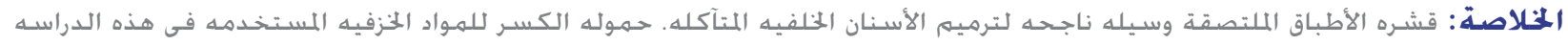

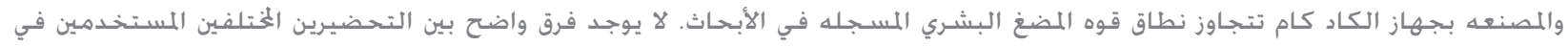

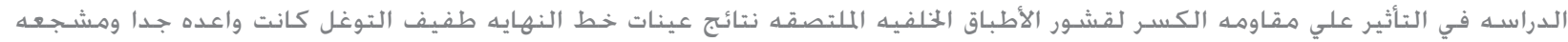

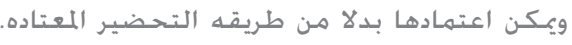

الكلمات المفتاحية: الكاد كام، الليثيوم داي سيليكات، قشره الأطباق الملتصقة، مقاومة الكسـر ، تصميمات التحضير 